\title{
Predictors of Malaria Prevalence and Coverage of Insecticide-Treated Bednets among Under-Five Children in the Buea Health District, South West Region, Cameroon
}

\author{
Mohamed Isah",2, Ngwa Fabrice Ambe3, Tanyi Pride Bobga ${ }^{3}$, Ateh Stanislas Ketum4, \\ Misonge Kapnang Ivan ${ }^{5}$, Mentoh Ajem Abungwi ${ }^{6}$ \\ ${ }^{1}$ Department of Public Health and Hygiene, Faculty of Health Sciences, University of Buea, Cameroon \\ ${ }^{2}$ Nkafu Policy Institute of the Denis and Lenora Foretia Foundation, Yaounde, Cameroon \\ ${ }^{3}$ Department of Medical Laboratory Science, Faculty of Health Sciences, University of Buea, Cameroon \\ ${ }^{4}$ Department of Medicine, Faculty of Health Sciences, University of Buea, Cameroon \\ ${ }^{5}$ Health Organisation Welfare, Yaounde, Cameroon \\ ${ }^{6}$ Department of Pharmacy, Faculty of Medicine and Pharmaceutical Sciences, University of Douala, Cameroon \\ Email: mohamedisahmi@gmail.com,ngwafabrice12@gmail.com, bobgatanyi@yahoo.com, atehstanislask@gmail.com, \\ ivan.misonge@yahoo.com, ajemsamira@gmail.com
}

How to cite this paper: Isah, M., Ambe, N.F., Bobga, T.P., Ketum, A.S., Ivan, M.K. and Abungwi, M.A. (2020) Predictors of Malaria Prevalence and Coverage of Insecticide-Treated Bednets among Under-Five Children in the Buea Health District, South West Region, Cameroon. Journal of Biosciences and Medicines, 8, 25-40. https://doi.org/10.4236/jbm.2020.82003

Received: November 11, 2019

Accepted: January 19, 2020

Published: January 22, 2020

Copyright $\odot 2020$ by author(s) and Scientific Research Publishing Inc. This work is licensed under the Creative Commons Attribution International License (CC BY 4.0).

http://creativecommons.org/licenses/by/4.0/

\section{(c) (i) Open Access}

\begin{abstract}
Introduction: Cameroon is a hyperendemic country to malaria where it remains a major public health concern, especially amongst children under-five. Insecticide-treated bednets (ITBNs) is the main control strategies. This study aimed at determining the predictors of malaria prevalence and coverage of ITBNs among under-five children in the Buea Health District (BHD), South West Region of Cameroon in other to reduce the morbidity and mortality of malaria. Methods: A cross-sectional study was carried out in the BHD which is a malaria-hyperendemic area. Every head (female/male) of the household who was present at home at the time of data collection was randomly interviewed using a structured questionnaire. Under-five children were ascertained for malaria using microscopy, with a temperature of $\geq 37.50^{\circ} \mathrm{C}$. Results: Out of 391 children (mean age $=19.7$ month, $\mathrm{SD}=2.5$ ) who were selected and ascertained for malaria, the overall malaria prevalence was $13.04 \%$ (95\% CI: 10.04 - 16.78). In a multivariate analysis after adjusting for confounders, female parents/guardians ( $\mathrm{AOR}=0.53,95 \% \mathrm{CI}: 0.29$ - 0.91) was associated with low risk of malaria while parents/guardians with no formal/primary educational ( $\mathrm{AOR}=3.3,95 \% \mathrm{CI}$ : $1.76-4.04$ ) and children who did not use ITBN $(\mathrm{AOR}=1.40,95 \% \mathrm{CI}: 1.08-2.51)$ were associated with an increased risk of malaria. Out of the selected children, $84.4 \%$ possessed ITBN (95\% CI: 80.4 -
\end{abstract}


87.7) while 72.6\% (95\% CI: 67.9 - 76.8) used ITBN. In a multivariate after adjusting for confounders, Bova health area showed a significantly lower usage of ITBNs $\left(\chi^{2}=14.053, \mathrm{p}=0.003\right)$. Conclusion: The findings indicate that increased ITBN usage, increased parents/guardians' educational level and good knowledge of ITBN is required to lower the risk of under-five children being infected with malaria. Health area of residence greatly influences the direct relationship between bednets possession and usage. These, therefore, indicates the possession of ITBN doesn't mean their usage. The Cameroon National malaria control programs should consider the realities of the living conditions of the population for the implementation of better policies.

\section{Keywords}

Malaria, Prevalence, Bednets, Children, Under-Five

\section{Introduction}

Malaria has constituted a global public health issue for decades, globally putting an estimated 3.4 billion people at risk, with 216 million cases and 450,000 deaths occurring in 2016 [1]. Most of them were found in sub-Saharan Africa, and most cases (77\%) concerned children under-five years old [1]. Plasmodium falciparum and Plasmodium vivax are the most significant pathogens, of which the former is the most deadly form predominating in Africa [1]. Pregnant women and under-five children are most vulnerable group. According to the Cameroon National Malaria Control Program (CNMCP), malaria accounts for approximately $53 \%$ of morbidity and $40 \%$ of mortality mostly among children under the age of five years [2].

Malaria is hyperendemic in Cameroon, where it is among the main cause of morbidity (41\%) and mortality (43\%) [2] [3]. It accounts for a heavy burden on the health care system and the economy of Cameroon. It constitutes $45 \%$ of medical consultations and 39\% of hospitalizations, $40 \%$ of household health expenditure and $26 \%$ of work absenteeism [3]. The consequent healthcare costs and loss in productivity result in an estimated annual loss of $1.3 \%$ of the Gross Domestic Product (GDP) to the national economy [3] [4].

Bednets impregnated with insecticides (permethrin or deltamethrin) has demonstrated to be a very effective and suitable method of malaria prevention if used properly [5]. Bednets are often used in areas where malaria is common, in which, it is mostly used as a tent-like covering over beds. The net prevents direct contact between the malaria vector (female anopheles mosquito) and the human skin. For effectiveness, it is important that the netting doesn't have holes or gaps large enough to allow the malaria vector (female anopheles mosquitoes) to penetrate. It is also important to "seal" the net well because malaria vectors can "squeeze" through improperly secured nets. The malaria vectors can also bite a person through the net; therefore, the net shouldn't rest directly in contact with the skin. 
Although numerous studies have suggested several factors that influence bednets coverage at the individual and household level in Africa [6] [7] [8] [9], there is limited information about the population demographics and their association with bednet coverage and malaria prevalence in Cameroon in general, and in the Buea Health District (BHD) specifically. Amidst a third nationwide mass-campaign of free distribution of Insecticide Treated Bednets (ITBNs) by the government through the Ministry of Public Health and National Malaria Control Committee (NMCC), the situation of bednet possession and usage remains worrying; this could be attributed to individual and household factors affecting possession and proper utilization [8]. According to the World Health Organisation (WHO) recommendations, it is important to investigate the impact of predictive factors on bednet possession and usage to boost bednet possession, acceptance and use for the fight against malaria. Therefore, this study sought to determine malaria prevalence and its predictive factors, and bednet coverage and its predictive factor. This, would, in turn, have a major bearing on the planning for success in ongoing and subsequent distribution efforts.

\section{Materials and Methods}

\subsection{Study Site}

The study site was the Buea Health District (BHD) (Figure 1). Buea is found in Fako Division in the South West Region of Cameroon. It encloses a total surface

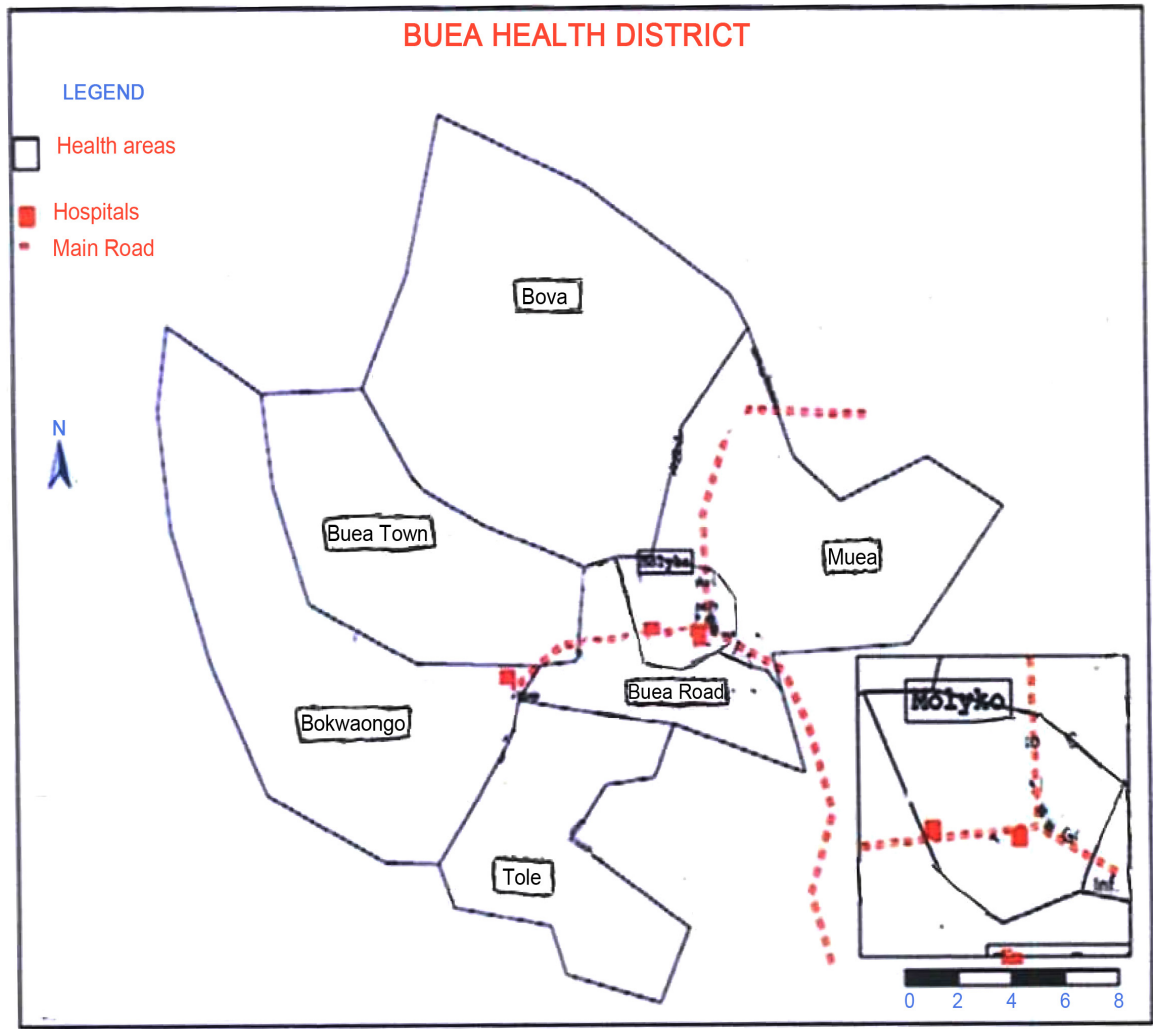

Figure 1. Adapted map of BHD showing the seven health areas [11] 
area of 870 square $\mathrm{km}$. It has an equatorial climate, and temperatures range between $21^{\circ} \mathrm{C}-28^{\circ} \mathrm{C}$. The town experiences two major seasons; a rainy season that begins in March and ends in October, and a dry season that begins in November and ends in February. Annual rainfall varies from 3000 to $5000 \mathrm{~mm}$. The BHD includes seven health areas (Bova, Muea, Molyko, Bokwaongo, Tole, Buea Town and Buea Road) with an estimated population of about 200,000 inhabitants, and is constituted essentially of Bakweri (the indigenes) [10]. English (the major) and French (the minor) are the two official languages used for general interaction while pidgin-English is the lingua franca. A health area represents a subset of a health district, which provides prevention and health promotion, to particular communities to have better health for all.

\subsection{Study Design}

It was a community-based study. This study used a cross-sectional design to sample all children less than five years in the Buea Health District (BHD). The study period was between November 2017 and May 2018. The respondents (parents or guardians) were given questionnaires designed in English, to assess bednets coverage (possession and usage), predictors of malaria prevalence, and predictors of ITBN coverage.

Data were collected using standardized data collection instruments that were field-pretested to ensure reliability and validity.

\subsection{Study Population and Sampling}

Children under five years of age and their parents or guardians, who were living in the Buea Health District, were included in the study. Guardians in this study involved anyone who has the powers and responsibilities of a parent concerning the child's support, care, education, health, and welfare.

Children in the study area without parents or guardians were excluded from the study.

A multi-stage sampling technique was used. The Buea Health District was placed into clusters of the seven health areas (Bova, Bokwango, Buea Road, Molyko, Muea, Buea Town and Tole). A simple random sampling of four health areas (Bova, Muea, Molyko, and Tole) was carried out. Afterward, from the randomly selected health areas, a random selection of eight communities (Bolikawo, Likombe, Bokova, Bwitingi, Ndongo, Mile 16, Lyongo and Bolu) was selected. Two communities were selected from each of the four health areas. Finally, under-five children were selected from the communities by an interval sampling method.

The number of participants was obtained based on the size of the population.

\subsection{Data Collection on the Field}

A structured questionnaire was used to record variables (demographic, dependent and some independent variable). Variables include:

1) Gender of child: Either of the two sexes (male or female); 
2) Age of parents or guardians: The length of time that he or she has lived or existed;

3) Gender of parents or guardians: Either of the two sexes (male or female);

4) Marital status of parents or guardians: This was defined as the legally defined marital state or union;

5) The educational level of parents or guardians: This refers to the highest level of education that he/she has completed;

6) Occupation of parents or guardians: This was defined as their job or profession;

7) Parents or guardians knowledge of malaria prevention: These were defined as facts, information, and skills acquired through experience or education that they have about malaria;

8) Health area of residence: This was considered as the area where participants lived, within the seven health area;

9) Malaria prevalence: It was the number of malaria cases in the population at the study time divided by the population at that time, expressed per 1000;

10) Bednets coverage: This was defined as the proportion of individuals reportedly having an ITBN over their sleeping space. That is the number of people who possessed and used bednets.

The participant's axillary temperature was then measured using a digital thermometer, with current fever defined as body temperature greater than or equal to $37.5^{\circ} \mathrm{C}$ took during the study. A sample of blood was collected from each participant, by pricking the finger of the participants and collecting capillary blood on a microscopic slide for parasitological analysis. Bednets was defined as either insecticide-treated bednets or long-lasting insecticide-treated bednets. Insecticide-treated bednets (ITBNs) was defined as a bednet that has to be retreated after every six months. Long-Lasting insecticidal bednets (ITBNs) were defined as insecticide-treated bednet as that which lasts 3 years before treatment. ITBN used were defined as those reportedly sleeping under a bednet the previous night. Parasitemia was defined as the presence of asexual malaria parasites on a thick blood film whereas malaria was defined as current fever together with parasitemia.

\subsection{Determination of Malaria Parasitaemia}

Thick and thin blood smears were prepared following standard procedures and stained with $10 \%$ Giemsa. The malaria parasitaemia status and density were determined under oil immersion with the 100x objective, 10x eyepiece of an Olympus CX23 Binocular Microscope, while the Plasmodium species were identified on the thin blood smear. A smear was only considered negative if no malaria parasites were seen in 50 high power fields. With each positive smear, the level of parasitaemia was estimated by counting the parasites against at least 200 leucocytes and assuming a leucocyte count of 8000 per microliter to calculate the number of parasites/ $\mu$ l blood [12]. 


\subsection{Data Management and Analysis}

Questionnaires were designed using Epi info version 7 and all data were entered into Microsoft Excel and analyzed using Statistical Package for the Social Sciences (SPSS) version 20 for windows. Data was collected using a questionnaire and checked for errors. Data were edited, coded and entered into a computer using Microsoft Excel software. Back up storage was done in CD and all raw data were stored safely in a computer secured with a password. The significance of the difference in prevalence was explored using Pearson's chi-square test whereas the differences in group means were assessed using Student's t-test, after checking the normality of distribution with the Kolmogorov-Smirnov test. Bivariate and multivariate logistic regression analysis was employed to examine the association between socio-demographic variables and other risk factors associated with malaria prevalence, and the factors associated with malaria were generated from the regression. Association analysis of malaria prevalence and ITBN usage was undertaken by logistic regression, using as covariates altitude, location, gender and age group. A p-value of less than 0.05 was considered statistically significant.

\section{Results}

\subsection{Socio-Demographic Characteristics of Participants}

The socio-demographic characteristics of the participants are summarised in $\mathrm{Ta}$ ble 1. A total of 391 parents or guardians and their under-five aged children participated in this study. The mean age of the children was $19.7(\mathrm{SD}=2.5)$ months.

Table 1. Socio-demographic characteristics of the participants $(n=391)$.

\begin{tabular}{cc}
\hline CHARACTERISTIC & No. (\%) \\
\hline Age of child (in months) & Mean \pm SD (19.7 \pm 2.5$)$ \\
$00-30$ & $294(75.19)$ \\
$31-60$ & $97(24.81)$ \\
Gender (Child) & $149(38.11)$ \\
Male & $242(61.89)$ \\
Female & Mean \pm SD (1.9 \pm 0.7$)$ \\
Number children (<5 years old) in the household & $303(77.49)$ \\
$3-5$ & $88(22.51)$ \\
Age of Parent/Guardian (in years) & Mean \pm SD (34.1 \pm 3.2$)$ \\
$<21$ & $32(8.2)$ \\
$21-40$ & $270(69.0)$ \\
$>40$ & $89(22.8)$ \\
Fender (Parent/Guardian) & $85(21.74)$ \\
Male & $306(78.26)$ \\
&
\end{tabular}




\section{Continued}

Marital status (Parent/Guardian)

$\begin{array}{lc}\text { Single } & 125(31.97) \\ \text { Married } & 235(60.10) \\ \text { ated/Widow(er) } & 31(7.93)\end{array}$

Separated/Widion (Parent/Guardian)

$\begin{array}{cc}\text { Civil servant } & 49(12.53) \\ \text { Housewife } & 19(4.86) \\ \text { Retired } & 5(1.28) \\ \text { Self-employed } & 242(61.89) \\ \text { Student } & 38(9.72) \\ \text { Unemployed } & 38(9.72)\end{array}$

Level of Education (Parent/Guardian)

No formal education

$12(3.07)$

Primary education

$103(26.34)$

Secondary education

$185(47.31)$

Tertiary education

$91(23.27)$

Religion (Parent/Guardian)

$\begin{array}{cc}\text { Traditionalist } & 6(1.53) \\ \text { Christians } & 375(95.91) \\ \text { Muslims } & 10(2.56)\end{array}$

Health Area

$\begin{array}{cc}\text { Bova } & 65(16.62) \\ \text { Molyko } & 93(23.79) \\ \text { Muea } & 130(33.25) \\ \text { Tole } & 103(26.34)\end{array}$

$\mathrm{SD}=$ Standard Deviation; No. $=$ Number of participants.

\subsection{Prevalence of Malaria among Under-Five Children}

The prevalence of malaria in children 00 - 59 months old was $13.04 \%$ (95\% CI: 10.04 - 16.78) (Figure 2).

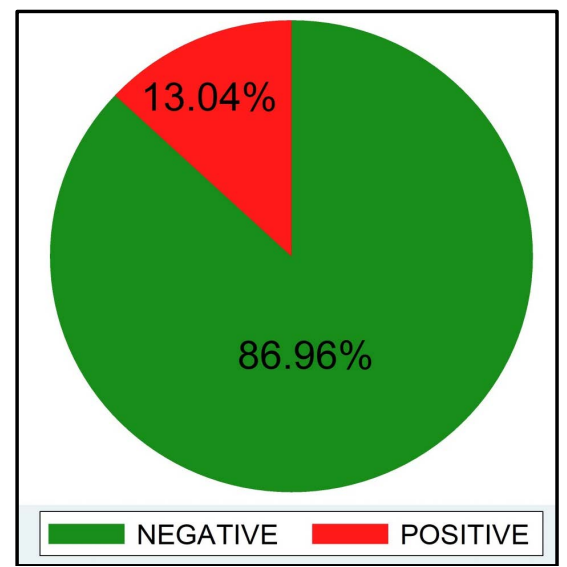

Figure 2. Prevalence of malaria among under-five children in the BHD. 


\subsection{Factors Associated with Malaria Prevalence among Under-Five Children in the BHD}

Association is explained by the chi-square test, and prediction by logistic regression. In the Bivariate analysis, the parents/guardians' educational level, the parents' knowledge on malaria prevention, the health area of residence and children use of ITBN were significantly associated with malaria in children aged less than 5 years. After adjusting for confounders in the multivariate analysis, only gender of parents, parents' educational level and children use of ITBN were significantly associated with malaria among children aged 00 - 59 months (Table 2), with gender of parents/guardian being a protective factor while parents' educational level and children use of ITBN being a risk factor.

The odds of having malaria was significantly lower among children whose parents/guardians were females (AOR: 0.53; 0.29 - 0.01) than males (Table 2). The odds of having malaria were significantly higher among children of parents with no formal or primary education (AOR: 3.30; 95\% CI: 1.76 - 4.40) compared to children whose parents had attained secondary and tertiary education. The odds of having malaria were significantly higher among children who did not effectively use or slept ITBN (AOR: 1.42; 95\% CI: 1.08 - 2.51) compared to children who used or slept under ITBN (Table 2).

Table 2. Factors associated with malaria prevalence among under-five children.

\begin{tabular}{|c|c|c|c|c|c|}
\hline \multirow{2}{*}{ Variable } & \multirow{2}{*}{ Categories } & \multicolumn{4}{|c|}{ Malaria } \\
\hline & & COR & $(95 \% \mathrm{CI})$ & AOR & $(95 \% \mathrm{CI})$ \\
\hline \multicolumn{6}{|l|}{ Age of child } \\
\hline & $00-30$ months & 1 & & 1 & \\
\hline & $31-60$ months & 0.82 & $0.42-1.65$ & 0.71 & $0.40-1.62$ \\
\hline \multicolumn{6}{|l|}{$\begin{array}{l}\text { Gender of } \\
\text { parent/guardian }\end{array}$} \\
\hline & Male & 1 & & 1 & \\
\hline & Female & 0.56 & $0.29-1.06$ & 0.53 & $0.29-0.91$ \\
\hline \multicolumn{6}{|c|}{$\begin{array}{l}\text { Educational level of } \\
\text { parent/guardian }\end{array}$} \\
\hline & Secondary/Tertiary & 1 & & 1 & \\
\hline & No formal/Primary & 2.94 & $1.61-5.30$ & 3.3 & $1.76-4.04$ \\
\hline \multicolumn{6}{|l|}{$\begin{array}{l}\text { Occupation of } \\
\text { parent/guardian }\end{array}$} \\
\hline & Employed & 1 & & 1 & \\
\hline & Unemployed & 1.72 & $0.92-3.21$ & 1.62 & $0.97-3.01$ \\
\hline \multicolumn{6}{|c|}{$\begin{array}{l}\text { Knowledge on } \\
\text { malaria prevention }\end{array}$} \\
\hline & Yes & 1 & & 1 & \\
\hline & No & 1.88 & $1.02-3.22$ & 1.65 & $0.94-2.13$ \\
\hline
\end{tabular}




\section{Continued}

Usage of ITBN (Child)

$\begin{array}{ccccc}\text { Used } & 1 & & 1 & \\ \text { Not used } & 1.41 & 1.04-2.68 & 1.40 & 1.08-2.51\end{array}$

Health Area

$\begin{array}{ccccc}\text { Bova } & 1 & & 1 & \\ \text { Molyko } & 1.02 & 0.74-2.11 & 1.01 & 0.68-2.07 \\ \text { Muea } & 1.51 & 1.01-2.41 & 1.42 & 0.75-2.38 \\ \text { Tole } & 1.04 & 0.77-2.08 & 1.03 & 0.69-2.17\end{array}$

No. $=$ Number of participants, ${ }^{\star}$ Statistical significant at $\mathrm{p}<0.05$.

\subsection{ITBN Coverage among Under-Five Children in the BHD}

The proportion of children who possessed ITBN was $84.4 \%$ (95\% CI: 80.4 - 87.7) while only $72.6 \%$ (95\% CI: 67.9 - 76.8) slept under or used the ITBN the previous night (Figure 3 ).

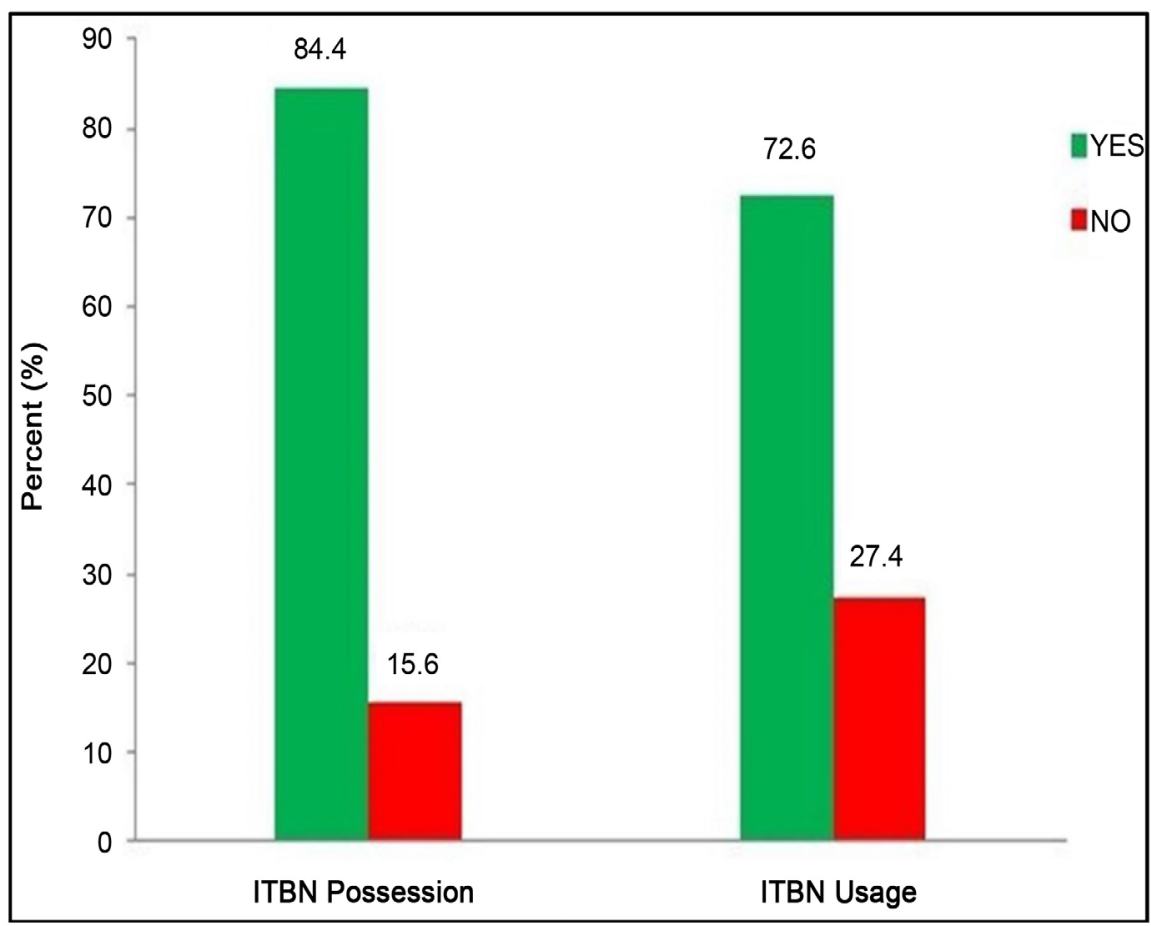

Figure 3. Proportion of children who possessed and used ITBN.

\subsection{Factors Associated to ITBN Usage among Under-Five Children in the BHD}

Only health area of residence showed a statistically significant $\left(\chi^{2}=14.053, \mathrm{p}=\right.$ 0.003 ) association with ITBN usage among children aged 00 - 59 months old. Bova Health Area showed a significantly lower (53.8\%) ITBN usage compared to the other 3 health areas with usage ranging from $74.8 \%-77.4 \%$ (Table 3 ). 
Table 3. Factors associated to ITBN usage among under-five children in the BHD.

\begin{tabular}{|c|c|c|c|c|}
\hline Factor & Category & $\begin{array}{c}\text { ITBN usage } \\
\text { No (\%) }\end{array}$ & $x^{2}$-value & p-value \\
\hline \multicolumn{5}{|l|}{ Age of child } \\
\hline & 00 - 30 months & $110(73.8)$ & 0.172 & 0.678 \\
\hline & $31-60$ months & $174(71.9)$ & & \\
\hline \multicolumn{5}{|l|}{ Gender of child } \\
\hline & Male & $209(71.1)$ & 1.306 & 0.253 \\
\hline & Female & $74(77.1)$ & & \\
\hline \multicolumn{5}{|l|}{ Age of parent/guardian } \\
\hline & $<21$ years & $23(71.9)$ & 0.017 & 0.999 \\
\hline & 21 - 40 years & $196(72.6)$ & & \\
\hline & $>40$ years & $65(73.0)$ & & \\
\hline \multicolumn{5}{|l|}{$\begin{array}{l}\text { Gender of } \\
\text { parent/guardian }\end{array}$} \\
\hline & Male & $62(72.9)$ & 0.005 & 0.942 \\
\hline & Female & $222(72.5)$ & & \\
\hline \multicolumn{5}{|l|}{ Marital status } \\
\hline & Single & $97(77.6)$ & 3.174 & 0.205 \\
\hline & Married & $163(69.4)$ & & \\
\hline & Separated/Widow & $24(77.4)$ & & \\
\hline \multicolumn{5}{|l|}{$\begin{array}{l}\text { Educational level of } \\
\text { parent/guardian }\end{array}$} \\
\hline & Secondary/Tertiary & $204(73.9)$ & 0.772 & 0.380 \\
\hline & No formal/Primary & $80(69.6)$ & & \\
\hline \multicolumn{5}{|l|}{ Occupation } \\
\hline & Employed & $209(71.8)$ & 0.378 & 0.539 \\
\hline & Unemployed & $75(75.0)$ & & \\
\hline \multicolumn{5}{|c|}{ Knowledge on malaria prevention } \\
\hline & Yes & $278(73.0)$ & 0.824 & 0.364 \\
\hline & Not & $6(60.0)$ & & \\
\hline \multicolumn{5}{|l|}{ Health Area } \\
\hline & Bova & $35(53.8)$ & 14.053 & 0.003 \\
\hline & Molyko & $72(77.4)$ & & \\
\hline & Muea & $100(76.9)$ & & \\
\hline & Tole & $77(74.8)$ & & \\
\hline
\end{tabular}

No. $=$ Number of participants. ${ }^{\star}$ Statistical significant at $\mathrm{p}<0.05$.

\section{Discussion}

The overall malaria prevalence among children under-five in this study was $13.04 \%$, which is lower than those found in other studies carried out in Cameroon, more specifically, the prevalence of $29.6 \%$ among children under 15 years 
of age revealed by Tobias et al. in 2015, southwest region [12], of 27\% reported by Fokam et al. in 2016 at the Tombel Health District [13] and the National prevalence of $15 \%$ reported by Tebit et al. in 2017 [14]. The lower prevalence of malaria in this study could be due to the fact that the parents/guardians of the children are highly knowledgeable (75\%) on the use of ITBN or the fact that there was a high coverage of ITBN among the under-five children, i.e. their possession $(84.4 \%)$ and usage $(72.6 \%)$ by parents. Also, the prevalence was higher than a prevalence by Ngum et al. in 2016 in some part of Mezam division, Northwest region [15] which was as $6.7 \%$. The lower prevalence in this study might be due to the difference in the environmental condition which affects the breeding site of mosquitoes. Nevertheless, this study was similar to that which was conducted by Fokam et al. in the same Health District (Buea Health District) which reported a prevalence of $13.4 \%$ among pregnant women [16].

Although a large number of studies carried out worldwide have identified a wide variety of risk factors, such as socioeconomic, environmental, demographic, and others associated with malaria [17] [18] [19], there is still a need to identify the influence of these factors in a local context to allow a successful formulation of a National Malaria Control Strategy.

In this study, the parents' or guardians educational level (no formal or primary education), the parents' knowledge on malaria prevention (not knowledgeable), the health area of residence (Muea) and children's use of ITBN (not used) were significantly associated with malaria in under-five children.

However, after adjusting for confounders, only parents/guardians' gender (males), parents/guardian educational level (low) and children's (low) use of ITBN were statistically significant to be affected by malaria. These findings could be used to provide intervention against malaria prevalence in this area. For example, in Ethiopia [19] scholars discovered that the majority of parents/guardians in the study had $<8$ years of education, which was a predictive factor of malaria infection. This was in agreement with our study where parents/guardians' education status was significantly associated (95\% CI: 1.76 - 4.04) with an increased risk for their children of being infected by malaria. A higher prevalence of malaria was found among under-five children whose parents/guardians had no for$\mathrm{mal} /$ primary education. This could be because knowledge of malaria prevention measures is essential to tackle it. ITBN usage was also significant (95\%: 1.08 2.51 ) with the prevalence of malaria, which was similar to a study in the Republic of Congo where researchers highlighted that [20] parents who did not use ITBN for their children had a higher risk of malaria infection than those who used it, confirming the supposed effectiveness of ITBN against malaria infection.

ITBN possession $(84.4 \%)$ and usage $(72.6 \%)$ have increased in the BHD as compared to that was carried out in 2015 in which the possession and usage were at $69.3 \%$ and $58.3 \%$ respectively [12]. The free distribution campaign has therefore recorded moderate gains in BHD thanks to the Ministry of Public Health. Nevertheless, the percentage of children using ITBNs is still below both 
the World Health Assembly [21] and the Ministry of Public Health target of $80 \%$ for an acceptable level of protection. Low rates of bednets usage reported by communities in the tropics are attributed primarily to lack of sufficient nets to cover all household members, but also to heat discomfort associated with poor airflow caused by bed nets [22]. Universal coverage mass distribution campaigns will be needed to achieve maximal public health impact and a successful "keep up" ITBN distribution strategy needs to be supplemented with periodic "catch up" campaigns. The government should, therefore, consider redistributing ITBNs to increase the coverage and also conduct enhanced health education and community mobilization efforts to increase the possession and proper utilization of insecticide-treated bed nets. ITBN possession and usage were lower in rural areas i.e. Bova and Tole and compared to urban and semi-urban i.e. Molyko and Muea settings despite the free distribution through health facilities. This finding is in agreement with other studies [23] [24] where inequalities were observed in ITBNs possession, with the poorest being disadvantaged. This pattern suggests that there might be barriers to persons from poorer communities obtaining ITBNs. These barriers might include population differences such as socioeconomic status [25] [26], reduced access to health facilities due to either distance or cost, poor quality health services, and less functional ITBN distribution system, or reduced knowledge about the health facility-based ITBN distribution program [27]. On the other hand, the greater density of health facilities for resource distribution in urban areas [28] may account for the lower ITBN possession in rural areas. An understanding of these dynamics is critical to evaluate current distribution programs as well as design future distribution strategies. These types of analyses, as well as reports on both ITBN possession and usage by all household members, are critical in monitoring progress towards universal coverage and identifying gaps in coverage, such as low use by particular age groups.

From this study, only the health area of residence showed a statistically significant $(\mathrm{p}<0.05)$, with Bova health area showing a lower ITBN usage compared to the other three health. Similar as in Bova health area in this study, recorded from studies in Zaria, Northern Nigeria where bednet usage was also low, and non-usage of bednets was attributed to factors such as negligence, heat, other factors including nets not tied up, washed, expired, dislike and house under construction), discomfort/suffocation and torn nets [29], which could have been in line with the factors that initiate the low usage of ITBN in Bova in this study.

In a similar study carried out in Northwest Region, Cameroon by Ntonifer et al., some of the respondents in the study said that using ITBN daily was boring and most of the time they were tired and lazy to use them. Others claimed that they did not like using nets because of the bad smell, the boring routine exercise of putting them up and down, and the feeling of suffocation. The heat was one of the main problems respondents encountered that could make them not to use ITBNs at times, as up to $52.2 \%$ of the respondents said the nets usually gave them heat [30]. 


\section{Limitations}

Study questionnaires were based on the use ITBNs the previous night. The use of ITBNs in the previous night may not reflect the actual regular use and there wasn't any night visit by interview to see if participants used the ITBNs.

Secondly, we cannot tag the reduction in malaria in BHD in 2018 solely to ITBNs in 2015, because there are also other control measures such as indoor residual spray and intermittent malaria treatment.

\section{Strength}

The study uses microscopy to diagnose malaria which is the gold standard.

\section{Conclusions}

1) The prevalence of malaria was relatively lower than the prevalence gotten from other studies carried out in the same health area.

2) Three factors, female parent/guardian, parents/guardians with no formal/primary education and children who do not use ITBN were more associated with malaria, with the gender of parents being protective while guardians/parents level educational and children use of ITBN being risks factors.

3) High coverage of ITBN usage was found among under-five children in the Buea Health District, with coverage greater than the WHO target of $80 \%$.

These, therefore, indicate that the act of government intervention is effective towards the reduction of malaria prevalence as a high proportion of participants were seen to possess and use bednets, but more efforts need to be done by the $\mathrm{CNMCP}$ to improve the correlation between bednets possession and usage.

\section{Acknowledgements}

We are grateful to the Delegate of Public Health of the South West Region and Community leaders for their cooperation and support.

We also appreciate parents/guardians of under-five children in the Buea Health District for their cooperation in data collection on their under-five children.

\section{Conflicts of Interest}

The authors declare no conflicts of interest regarding the publication of this paper.

\section{Ethical Approval and Consent for Participation}

The study was approved by the Institutional Review Board of the Faculty of Health Sciences, University of Buea, Cameroon (Ref: 2018/203/UB/SG/IRB/FHS) while administrative authorization was obtained from the South West Regional Delegation of Public Health (Ref: 211/MINSANTE/SW/RDPH/PS/326/968). Written assent was obtained from all the parents/guardians of under-five children living in the Buea Health District that participated in the study. 


\section{Availability of Data and Materials}

The dataset and materials of the study are available through the author MI and will be made accessible on request at the following e-mail:

mohamedisahmi@gmail.com.

\section{Funding}

The designing, data collection, analysis, and interpretation and manuscript writing for this study were funded by the authors.

\section{Authors' Contributions}

MI participated in the conception, design, data collection, data management, data analysis, drafting and revising the manuscript for academic content search and interpretation. NFA participated in the literature review, drafting, data collection and reviewing the manuscript. TPB participated in the conception, design, data collection and data analysis. ASK participated in data collection, design, drafting, and correction of the final manuscript. IMK participated in data analysis, management and interpretation. MAA participated in data collection, data management and interpretation. All authors read and approved the final copy.

\section{References}

[1] World Health Organization, Fact Sheet: World Malaria Report. http://www.who.int/malaria/media/world-malaria-report-2017/en/

[2] Nsagha, D.S., Elat, J.B.N., Ndong, P.A.B., Tata, P.N., Tayong, M.N.N., et al. (2012) Feasibility of Home Management Using ACT for Childhood Malaria Episodes in an Urban Setting. Drug, Healthcare and Patient Safety, 4, 1-18. https://doi.org/10.2147/DHPS.S25406

[3] Van Bortel, W., Chinh, V.D., Berkvens, D., Speybroeck, N., Trung, H.D. and Coosemans, M. (2009) Impact of Insecticide-Treated Nets on Wild Pyrethroid Resistant Anopheles Epiroticus Population from Southern Vietnam Tested in Experimental Huts. Malaria Journal, 86, 764-774. https://doi.org/10.1186/1475-2875-8-248

[4] World Health Organization (2012) Global Malaria Program. Malaria Journal, 24.

[5] Bhatt, S., Weiss, D., Cameron, E., Bisanzio, D., Mappin, B., et al. (2015) The Effect of Malaria Control on Plasmodium falciparum in Africa between 2000 and 2015. Nature, 526, 207-211.

[6] Rehman, A.M., Coleman, M., Schwabe, C., Baltazar, G., Matias, A., Gomes, I.R., Yellott, L., Aragon, C., Nchama, G.N., Mzilahowa, T., Rowland, M. and Kleinschmidt, I. (2011) How Much Does Malaria Vector Control Quality Matter: The Epidemiological Impact of Holed Nets and Inadequate Indoor Residual Spraying. PLoS ONE, 6, e19205. https://doi.org/10.1371/journal.pone.0019205

[7] Baume, A.C. and Marin, M.C. (2007) Intra-Household Mosquito Net Use in Ethiopia, Ghana, Mali, Nigeria, Senegal, and Zambia: Are Nets Being Used? Who in the Household Uses Them? The American Journal of Tropical Medicine and Hygiene, 77, 963-971. https://doi.org/10.4269/ajtmh.2007.77.963

[8] Dye, D.V.T., Apondi, R., Lugada, S.E., Kahn, G.J., Smith, J. and Othoro, C. (2010) Before We Used to Get Sick All the Time: Perceptions of Malaria and Use of Long 
Lasting Insecticide-Treated Bednets (LLINs) in a Rural Kenyan Community. Malaria Journal, 9, 345. https://doi.org/10.1186/1475-2875-9-345

[9] Graves, M.P., Ngondi, M.J., Hwang, J., Getachew, A., Gebre, T., Mosher, W.A., Patterson, E.A., Shargie, B.E., Tadesse, Z., Wolkon, A., Reithinger, R., Emerson, M.P. and Richards Jr., F.O. (2010) Factors Associated with Mosquito Net Used by, Individuals in Households Owning Nets in Ethiopia. Malaria Journal, 10, 354. https://doi.org/10.1186/1475-2875-10-354

[10] Nsagha, D., Njunda, A., Kamga, H., Assob, J. and Bongkem, E. (2012) HIV-1/HIV-2 Coinfection among Voluntary Counseling Testing Subjects at a Regional Hospital in Cameroon. African Health Sciences, 12, 276-281. https://doi.org/10.4314/ahs.v12i3.5

[11] Egbe, T.O., Omeichu, A., Halle-Ekane, G.E., et al. (2015) Prevalence and Outcome of Teenage Hospital Births at the Buea Health District, South West Region, Cameroon. Reproductive Health, 12, Article No. 118. https://doi.org/10.1186/s12978-015-0109-5

[12] Apinjoh, T.O., Anchang-Kimbi, J.K., Mugri, R.N., Tangoh, D.A., Nyingchu, R.V., et al. (2015) The Effect of Insecticide Treated Nets (ITBNs) on Plasmodium falciparum Infection in Rural and Semi-Urban Communities in the South West Region of Cameroon. PLoS ONE, 10, e0116300. https://doi.org/10.1371/journal.pone.0116300

[13] Fokam, E.B., Dzi, T.J., Ngimuh, L. and Eyong, P. (2016) The Effect of Long Lasting Insecticide Bed Net Use on Malaria Prevalence in the Tombel Health District, South West Region-Cameroon. Malaria Research and Treatment, 2016, Article ID: 3216017. https://doi.org/10.1155/2016/3216017

[14] Tebit, E.K., Tayong, D.B., Andreas, L., Longdoh, N. and Theresa, N. (2017) Epidemiological and Clinical Profile of Paediatric Malaria: A Cross Sectional Study Performed on Febrile Children in Five Epidemiological Strata of Malaria in Cameroon. BMC Infectious Diseases, 17, 499. https://doi.org/10.1186/s12879-017-2587-2

[15] Ngum, H.N. and Serophine, V. (2016) Assessing the Effective Use of Mosquito Nets in the Prevention of Malaria in Some Parts of Mezam Division Northwest Region Cameroon. Malaria Journal, 15, 390. https://doi.org/10.1186/s12936-016-1419-y

[16] Fokam, E.B., Ngimuh, L., Anchang-Kimbi, J. and Wanji, S. (2016) Assessment of the Usage and Effectiveness of Intermittent Preventive Treatment and Insecticide-Treated Nets on the Indicators of Malaria among Pregnant Women Attending Antenatal Care in the Buea Health District Cameroon. Malaria Journal, 15, 172. https://doi.org/10.1186/s12936-016-1228-3

[17] Gahutu, J.B., Steininger, C., Shyirambere, C., Zeile, I., Cwinya-Ay, N., Danquah, I., et al. (2011) Prevalence and Risk Factors of Malaria among Children in Southern Highland Rwanda. Malaria Journal, 10, 134. https://doi.org/10.1186/1475-2875-10-134

[18] Ayele, D., Zewotir, T. and Mwambi, H. (2012) Prevalence and Risk Factors of Malaria in Ethiopia. Malaria Journal, 11, 195. https://doi.org/10.1186/1475-2875-11-195

[19] Ayele, D., Zewotir, T. and Mwambi, H. (2013) The Risk Factor Indicators of Malaria in Ethiopia. International Journal of Medical Sciences, 5, 335-347.

[20] Messina, J.P., Taylor, S.M., Meshnick, S.R., Linke, A.M., Tshefu, A.K., Atua, B., et al. (2011) Population, Behavioural and Environmental Drivers of Malaria Prevalence in the Democratic Republic of Congo. Malaria Journal, 10, 161. https://doi.org/10.1186/1475-2875-10-161 
[21] Korenromp, E., Miller, J., Cibulskis, R., Kabir, C.M., Alnwick, D., et al. (2003) Monitoring Mosquito Net Coverage for Malaria Control in Africa: Possession vs. Use by Children under 5 Years. Tropical Medicine \& International Health, 8, 693-703. https://doi.org/10.1046/j.1365-3156.2003.01084.x

[22] Ministry of Public Health, Cameroon (2009) Health Sector Strategy 2001-2015. 109.

[23] von Seidlein, L., Konstantin, I., Bruun, R., Jawara, M., Pinder, M., et al. (2012) Airflow Attenuation and Bed Net Utilization: Observations from Africa and Asia. Malaria Journal, 11, 200. https://doi.org/10.1186/1475-2875-11-200

[24] Ahmed, S.M. and Zerihun, A. (2010) Possession and Usage of Insecticidal Bed Nets among the People of Uganda: Is BRAC Uganda Health Programme Pursuing a Pro-Poor Path? PLoS ONE, 5, e12660. https://doi.org/10.1371/journal.pone.0012660

[25] Sena, L.D., Deressa, W.A. and Ali, A.A. (2013) Predictors of Long-Lasting Insecticide-Treated Bednet Ownership and Utilization: Evidence from Community-Based Cross-Sectional Comparative Study, Southwest Ethiopia. Malaria Journal, 12, 406. https://doi.org/10.1186/1475-2875-12-406

[26] Temu, E.A., Coleman, M., Abilio, A.P. and Kleinschmidt, I. (2012) High Prevalence of Malaria in Zambezia, Mozambique: The Protective Effect of IRS versus Increased Risks Due to Pig Keeping and House Construction. PLoS ONE, 7, e31409. https://doi.org/10.1371/journal.pone.0031409

[27] Skarbinski, J., Mwandama, D., Luka, M., Jafali, J., Wolkon, A., et al. (2011) Impact of Health Facility-Based Insecticide Treated Bednet Distribution in Malawi: Progress and Challenges towards Achieving Universal Coverage. PLOS ONE, 6, e21995. https://doi.org/10.1371/journal.pone.0021995

[28] Kazembe, L., Appleton, C. and Kleinschmidt, I. (2007) Geographical Disparities in Core Population Coverage Indicators for Malaria in Malawi. International Journal for Equity in Health, 6, 5. https://doi.org/10.1186/1475-9276-6-5

[29] Renne, P.E., Kirby, K. and Akkineni, R. (2007) Bednet Use and Malaria Knowledge in Zaria City, Nigeria. Journal of the International Institute, 15, 2.

[30] Ntonifor, N.H. and Veyufambom, S. (2016) Assessing the Effective Use of Mosquito Nets in the Prevention of Malaria in Some Parts Mezam Division, Northwest Region Cameroon. Malaria Journal, 15, 390. https://doi.org/10.1186/s12936-016-1419-y

\section{Abbreviations}

AOR: Adjusted odd ratio; COR: Crude odd ratio; GDP: Gross domestic product; ITBN: Insecticide-treated bednets; IRS: Indoor residual spray; ITBN: Long-lasting insecticide-treated bednets; CNMCP: Cameroon National malaria control program; SSPSS: Statistical package for social science; BHD: Buea Health District. 